\title{
Spray-assisted layer-by-layer assembly on hyaluronic acid scaffolds for skin tissue engineering
}

\author{
Isa P. Monteiro, ${ }^{1,2,3}$ Anita Shukla, ${ }^{1 *}$ Alexandra P. Marques, ${ }^{2,3}$ Rui L. Reis, ${ }^{2,3}$ Paula T. Hammond ${ }^{1}$ \\ ${ }^{1}$ Department of Chemical Engineering, Massachusetts Institute of Technology, 77 Massachusetts Avenue, Cambridge, \\ Massachusetts 02139 \\ 23B's Research Group, Biomaterials, Biodegradables and Biomimetics, University of Minho, Headquarters of the European \\ Institute of Excellence on Tissue Engineering and Regenerative Medicine, AvePark, 4806-909 Caldas das Taipas, Guimarães, \\ Portugal \\ ${ }^{3}$ ICVS/3B's, PT Government Associate Laboratory, Braga/Guimarães, Portugal
}

Received 17 January 2014; revised 11 March 2014; accepted 19 March 2014

Published online 3 April 2014 in Wiley Online Library (wileyonlinelibrary.com). DOI: 10.1002/jbm.a.35178

\begin{abstract}
Tissue engineering approaches for the development of a single epidermal-dermal scaffold to treat fullthickness skin defects have been limited by difficulties in the fabrication of a bilayer scaffold combining the specific properties of the epidermis and the dermis. Here we present an innovative approach to developing a scaffold that holds promise for skin tissue engineering. We utilize the sprayassisted layer-by-layer assembly technique to deposit a polyelectrolyte multilayer film composed of hyaluronic acid and poly-L-lysine (the epidermal component) on a porous hyaluronic acid scaffold (the dermal component), in a rapid and controlled manner. The multilayer film promotes cell adhesion, contributing to regeneration of the epidermal barrier
\end{abstract}

functions of skin. While human keratinocytes attached and proliferated on the coated porous scaffolds, they did not invade the porous dermal component, thus leaving room for seeding of relevant fibroblast cell types in this scaffold. This scaffold therefore holds promise for co-culture of different cells, which may be useful for treatment of full-thickness skin defects as well as other tissue engineering applications. (c) 2014 Wiley Periodicals, Inc. J Biomed Mater Res Part A: 103A: 330340, 2015.

Key Words: spray-assisted layer-by-layer assembly, polyelectrolyte multilayer films, skin tissue engineering, hyaluronic acid

How to cite this article: Monteiro IP, Shukla A, Marques AP, Reis RL, Hammond PT. 2015. Spray-assisted layer-by-layer assembly on hyaluronic acid scaffolds for skin tissue engineering. J Biomed Mater Res Part A 2015:103A:330-340.

\section{INTRODUCTION}

Clinical management of wounds, burns, and nonhealing ulcers remains challenging, especially for deep and extensive lesions. ${ }^{1}$ Any loss of skin of $>4 \mathrm{~cm}$ in diameter will be unable to heal properly without a graft. ${ }^{2}$ Grafting is limited by the availability of donor skin. ${ }^{3}$ Skin tissue engineering remains a valid option to treat difficult skin defects. The scaffold should act as a biodegradable template to mimic the natural skin microenvironment, containing both the barrier function of the epidermal component and the mechanical stability and elasticity of the dermal component. ${ }^{4}$ Despite many efforts, the only commercially available bilayer scaffold for skin that allows permanent wound closure is difficult to generate and has high production costs. ${ }^{5-8}$ This bilayer scaffold is based on a hyaluronic acid (HA) ester, and it incorporates a dermal substitute (Hyalograft3D $($ ) and an epidermal replacement autograft (Laserskin $®)^{9}$ for use as a scaffold for autologous cells. Because the two independent structures need to be applied consecutively to the wound, this scaffold cannot be considered a 'true' dermal-epidermal skin substitute. ${ }^{5}$ In addition, this commercial scaffold usually requires the fixation of a non-degradable medical-grade synthetic elastomer on top of the scaffold, which has to eventually be removed. ${ }^{10}$ A skin substitute composed of epidermal and dermal layers in a single structure would reduce the number of surgical interventions and consequently, the cost associated with skin regenerative therapies. However, the lack of a cost-effective fabrication method to produce constructs combining epidermal and dermal layers has been a major limitation.

We investigated the layer-by-layer (LbL) assembly technique as a facile, cost-effective method to create a single

*Present affiliation: School of Engineering, Center for Biomedical Engineering, Institute for Molecular and Nanoscale Innovation, Brown University, Providence, Rhode Island, 02912, USA

Correspondence to: A. Shukla; e-mail: anita_shukla@brown.edu

Contract grant sponsor: Portuguese Foundation for Science and Technology; contract grant number: BD/39396/2007

Contract grant sponsors: MIT-Portugal Program; National Science Foundation Graduate Research Fellowship 


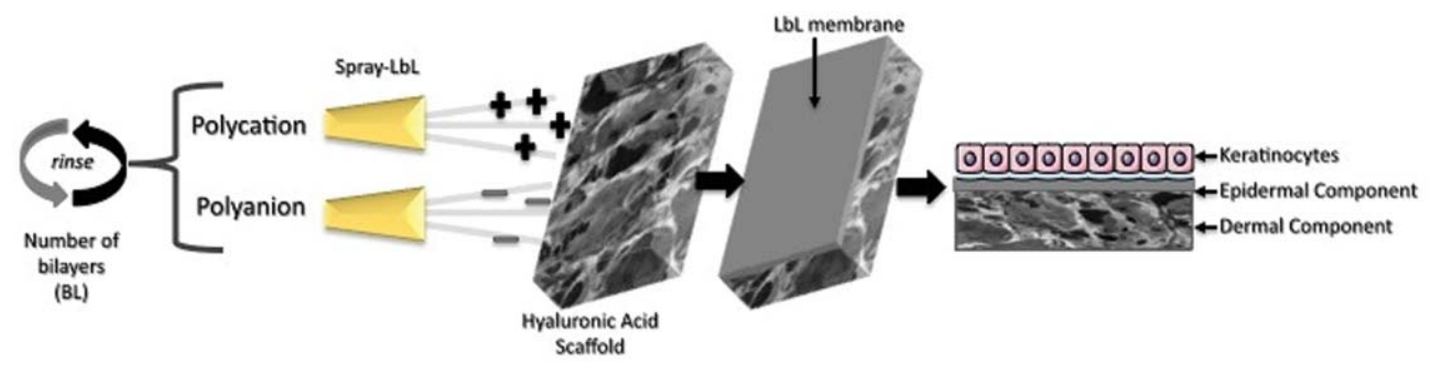

FIGURE 1. Schematic of the approach. The polycation, poly-L-lysine, and the polyanion, hyaluronic acid, are sprayed on top of the hyaluronic acid porous scaffold, creating a layer-by-layer membrane. Keratinocytes are seeded on top of the membrane, forming a cell monolayer. The layer-by-layer membrane acts as an epidermal substitute, which adheres to the dermal component (the porous hyaluronic acid scaffold). [Color figure can be viewed in the online issue, which is available at wileyonlinelibrary.com.]

epidermal-dermal substitute. We developed a bioactive LbL membrane on top of a porous dermal scaffold using HA and poly-L-lysine (PLL), which have been successfully used in numerous other bioactive LbL films. ${ }^{11-13} \mathrm{HA}$ is an anionic polysaccharide composed of repeating disaccharide units of D-glucuronic acid and $N$-acetyl-D-glucosamine, ${ }^{14}$ with a $\mathrm{p} K_{\mathrm{a}}$ of $2.9^{15}$ and hence a net charge of -1 per repeat unit at physiologic $\mathrm{pH}$ of 7.4. It is a native extracellular matrix macromolecule that serves a mechanical and structural role in vivo, ${ }^{16}$ enhances angiogenesis, participates in tissue hydration and promotes scarless wound healing. ${ }^{17-22}$ PLL is a linear polyisopeptide, ${ }^{23}$ with a $\mathrm{p} K_{\mathrm{a}}$ of 9 ; it is positively charged in physiologic conditions. PLL has been used extensively in several biomedical applications include drug and gene delivery and promotion of cellular adhesion. ${ }^{24}$ It has also been used to functionalize HA gels in order to improve cell attachment. ${ }^{25}$

In this work, we took advantage of the properties of HA and PLL to efficiently produce a stable membrane (the epidermal component), which is adsorbed on top of a porous HA scaffold (the dermal component), thus creating a single three-dimensional epidermal-dermal scaffold for eventual use in full-thickness skin regeneration. The porous HA scaffold is formed from lyophilization and acts as a negatively charged substrate, in which aerosolized solutions of the positively charged PLL and the negatively charged HA are sprayed sequentially, with intermediate rinses (see Fig. 1). The oppositely charged species adsorb to the growing LbL film at rates that enable nanometer-scale control over the film thickness. ${ }^{26}$ We opted to use spray-LbL assembly, rather than the traditional dip-LbL assembly technique, because the speed of assembly prevents excessive swelling of the HA scaffold during film assembly. As with the traditional dip-LbL assembly technique, spray-LbL assembly allows for the manipulation of the chemical, physical, and surface properties of multilayer film architectures by simply changing properties such as $\mathrm{pH}$ and ionic strength of the deposition solutions. ${ }^{27-29}$ Furthermore, previous work has shown that spray-LbL can be used to form conformal coatings on top of porous membranes by bridging the pores on the top surface of the membrane rather than penetrating the entire depth of the membrane. ${ }^{27,30}$ Our approach focused on studying the assembly behavior and bioactivity of the electrostatically assembled (PLL/HA) multilayer film.
We examined the film growth properties along with the ability to promote adhesion and proliferation of keratinocytes on these (PLL/HA) films deposited on both flat substrates and on the porous HA scaffold.

\section{MATERIALS AND METHODS}

\section{Materials}

Hyaluronic acid (HA) with molecular weight (MW) of 64 $\mathrm{kDa}$, 351-600 kDa, and 1.2-1.8 MDa was purchased from LifeCore Biomedical (Chaska, MN). Adipic acid dihydrazide $(\mathrm{ADH})$, sodium acetate buffer, 1-ethyl-3-[3-(dimethylamino)propyl]carbodiimide (EDC), sodium hydroxide $(\mathrm{NaOH})$, hydrochloric acid ( $\mathrm{HCl})$, hydroxybenzotriazole (HOBt), sodium periodate $\left(\mathrm{NaIO}_{4}\right)$, ethylene glycol, poly-L-lysine (PLL) hydrobromide (MW 40-60 kDa), phosphate buffered saline (PBS), hyaluronidase, osmium tetroxide, sucrose, acetate veronal, and dimethyl sulfoxide were acquired from Sigma-Aldrich (St. Louis, MO). Dialysis membranes (MW cut-off of $3.5 \mathrm{kDa}$ ) were purchased from Spectrum Labs (Rancho Dominguez, CA). Progenitor cell target media (CnT57) and 3D prime differentiation media (CnT-02-3DP) were obtained from CELLnTEC (Bern, Switzerland). Millicell cell culture inserts $(0.4-\mu \mathrm{m}$ pore size polycarbonate, $12 \mathrm{~mm}$ filter diameter) were obtained from Millipore (Billerica, MA). Biopsy punches were obtained from HealthLink (Jacksonville, FL). Human adult keratinocytes, penicillin/streptomycin, Quant-IT ${ }^{\mathrm{TM}}$ PicoGreen ${ }^{\circledR}$ dsDNA kit and LIVE/DEAD ${ }^{\circledR}$ viability/cytotoxicity kit for mammalian cells were obtained from Invitrogen Life Technologies ${ }^{\text {TM }}$ (Carlsbad, CA). Paraformaldehyde, glutaraldehyde, and sodium cacodylate were purchased from Electron Microscopy Sciences (Hatfield, PA). Silicon wafers were acquired from SiliconQuest International (Santa Clara, CA).

\section{Preparation of porous scaffolds}

Fermentation-derived HA was modified to both aldehyde (ALD) and hydrazide (ADH) forms, as described by others. ${ }^{31}$ For the ALD form, HA (MW 351-600 kDa) was dissolved in ultrapure water at a concentration of $0.5 \% \mathrm{w} / \mathrm{v}$. ADH was added in excess and allowed to dissolve completely; the $\mathrm{pH}$ was then adjusted to 6.8. EDC (5 $\mathrm{mM})$ and HOBt (5 $\mathrm{mM})$ were separately dissolved in a solution of 1:1 dimethyl sulfoxide and double distilled water. Both solutions were sequentially added to the HA-ADH mixture drop-wise. After 


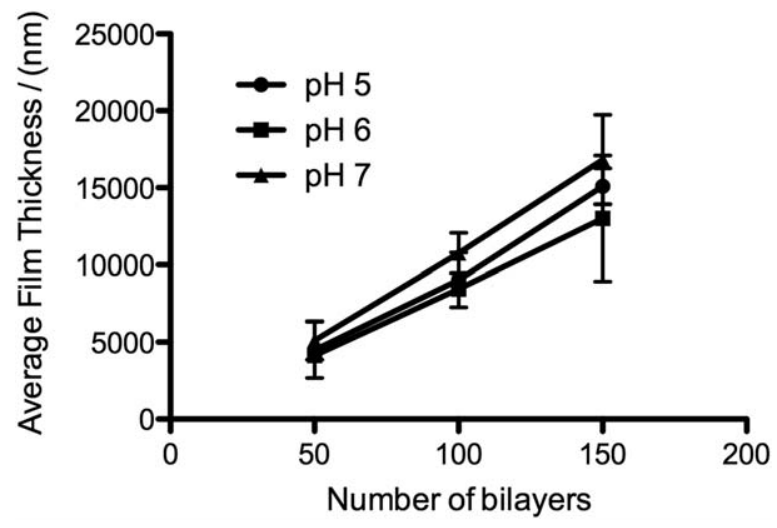

FIGURE 2. Average film thickness of sprayed (poly-L-lysine/hyaluronic

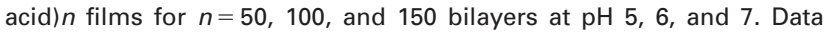
are mean \pm standard deviation, compared by one-way ANOVA Tukey's post hoc multiple comparison test. No significant differences were found between the different $\mathrm{pH}$ values used: $p$ value $=0.8591$ for one-way ANOVA.

stirring overnight, the modified HA was dialyzed and freezedried. For the ADH form, HA (MW 1.2-1.8 MDa) was dissolved in water at a concentration of $10 \mathrm{mg} \mathrm{mL}^{-1}$. Sodium periodate was dissolved in 5-10 mL of distilled water and added drop wise. After $2 \mathrm{~h}$ of stirring, ethylene glycol was added to stop the reaction. After $1 \mathrm{~h}$ of stirring, the modified HA was dialyzed and freeze-dried for 5 days. The ALD and the ADH were separately dissolved in deionizeddistilled water at a concentration of $40 \mathrm{mg} \mathrm{mL}^{-1}$. The two solutions were then mixed to promote HA crosslinking. The scaffolds were obtained by freeze-drying the crosslinked gels.

Pore size of the freeze-dried HA scaffolds was determined by using scanning electron microscopy (JEOL 5600LV SEM, Peabody, MA). Before observation, the scaffolds were coated with an ultrathin $(10 \mathrm{~nm})$ gold layer using a Hummer 6.2 Sputtering System (Anatech, Battle Creek, MI). The SEM images obtained where used to measure-length of pores using AxioVision Software (Zeiss, Germany) and obtain an average pore size. When the pores were not perfectly round, the length was measured as the largest diameter in each pore.

Spray-assisted layer-by-layer assembly of (PLL/HA) films A solution of $2.5 \mathrm{mM}$ sodium acetate buffer was prepared from a $3 \mathrm{M}$ stock solution and used for rinsing during LbL assembly and to dissolve the polyanion, HA, (64 KDa) and the polycation, PLL, at a concentration of $1 \mathrm{mg} \mathrm{mL}^{-1}$ and $\mathrm{pH} \mathrm{5,} \mathrm{6,} \mathrm{or} \mathrm{7.} \mathrm{Films} \mathrm{were} \mathrm{either} \mathrm{sprayed} \mathrm{on} \mathrm{silicon} \mathrm{wafers}$ or on porous HA scaffolds. Prior to film assembly on silicon, the wafers were cut into pieces $(4 \mathrm{~cm} \times 3 \mathrm{~cm})$, cleaned using methanol and deionized water, dried with compressed nitrogen and plasma etched using air in a Harrick PDC-32G plasma cleaner (Harrick Scientific, Pleasantville, NY) at high radio frequency (RF) level. Immediately following plasma etching, the substrates were submerged in PLL overnight at $4^{\circ} \mathrm{C}$. For films deposited on the HA scaffolds, the scaffolds were used as made without any plasma etching or addi- tional treatment. An automated spray-assisted LbL system (Svaya Nanotechnologies, Sunnyvale, CA) was used to deposit the film. The architecture of the films is denoted (PLL/HA) $n$, where $n$ represents the number of bilayers deposited ( $n$ of 50,100, and 150 was investigated in this work). Sodium acetate buffer diluted in PBS at a concentration of $2.5 \mathrm{mM}$ was sprayed between the cation and the anion deposition steps for rinsing (the $\mathrm{pH}$ was matched to the $\mathrm{pH}$ of the cation and anion solutions). Each HA and PLL deposition step lasted $2 \mathrm{~s}$ and each spray of rinsing solution was $3 \mathrm{~s}$, with a flow rate of $0.25 \mathrm{~mL} \mathrm{~s}^{-1}$. After depositing LbL films on silicon, the films were dried under nitrogen and stored at $4^{\circ} \mathrm{C}$ until subsequent use. After spraying the LbL films on the scaffolds, the substrates were allowed to dry and a biopsy punch was used to produce smaller coated scaffolds for subsequent experiments (8-mm diameter, $\sim 3$-mm thick) which were stored at $4^{\circ} \mathrm{C}$ until they were used.

Film growth, morphology, and erosion characterization Film growth and morphology were characterized on LbL film-coated silicon wafers. Film growth was measured using a surface profilometer (Dektak 150 Surface, Veeco, Plainview, NY). The dried films were scratched using a sharp razor and three measurements were taken over a 100micrometer length per scratch. For each film deposition condition, the roughness and the step height of three samples was determined. The topography and roughness of the different films was analyzed using a Dimension 3100 Nanoman atomic force microscope (Veeco Metrology, Santa Barbara, CA). SEM was also used to observe the films deposited either on top of the silicon wafers or on top of the scaffolds after sputtering with gold as described earlier.

Erosion of (PLL/HA)150 films assembled at $\mathrm{pH} 7$ on silicon wafers was evaluated by incubating the samples in PBS solution with or without the enzyme hyaluronidase on an orbital shaker at $37^{\circ} \mathrm{C}$. Film thickness loss was tracked by drying these films and using the profilometer to monitor film thickness in the same way in which film growth was quantified. Normalized film thickness was obtained at each time point by dividing the average of thickness measured for four samples by the average of thickness measured for the same samples before starting the film erosion study in PBS.

\section{Cell culture on film-coated substrates}

Human keratinocytes were expanded in CnT-57 medium with $1 \%$ penicillin/streptomycin. Cells at passage 3 were used in the study. Film-coated silicon wafers $\left(1 \mathrm{~cm}^{2}\right)$ were placed in 12-well culture plates (one piece per well). Keratinocytes $\left(2 \times 10^{5}\right.$ cells $)$ were seeded directly on the top of each film-coated silicon wafer in $400 \mu \mathrm{L}$ of CnT-57 media. After 5 h, 1 mL of CnT-57 media was added to each well.

The film-coated scaffolds were placed individually inside $12 \mathrm{~mm}$ inserts with a pore size of $0.4-\mu \mathrm{m}$. The inserts containing the scaffolds were then placed into a $60-\mathrm{mm}$ cell culture dish. After wetting the inserts and the scaffolds with media, $2 \times 10^{5}$ keratinocytes were seeded on each scaffold 
A

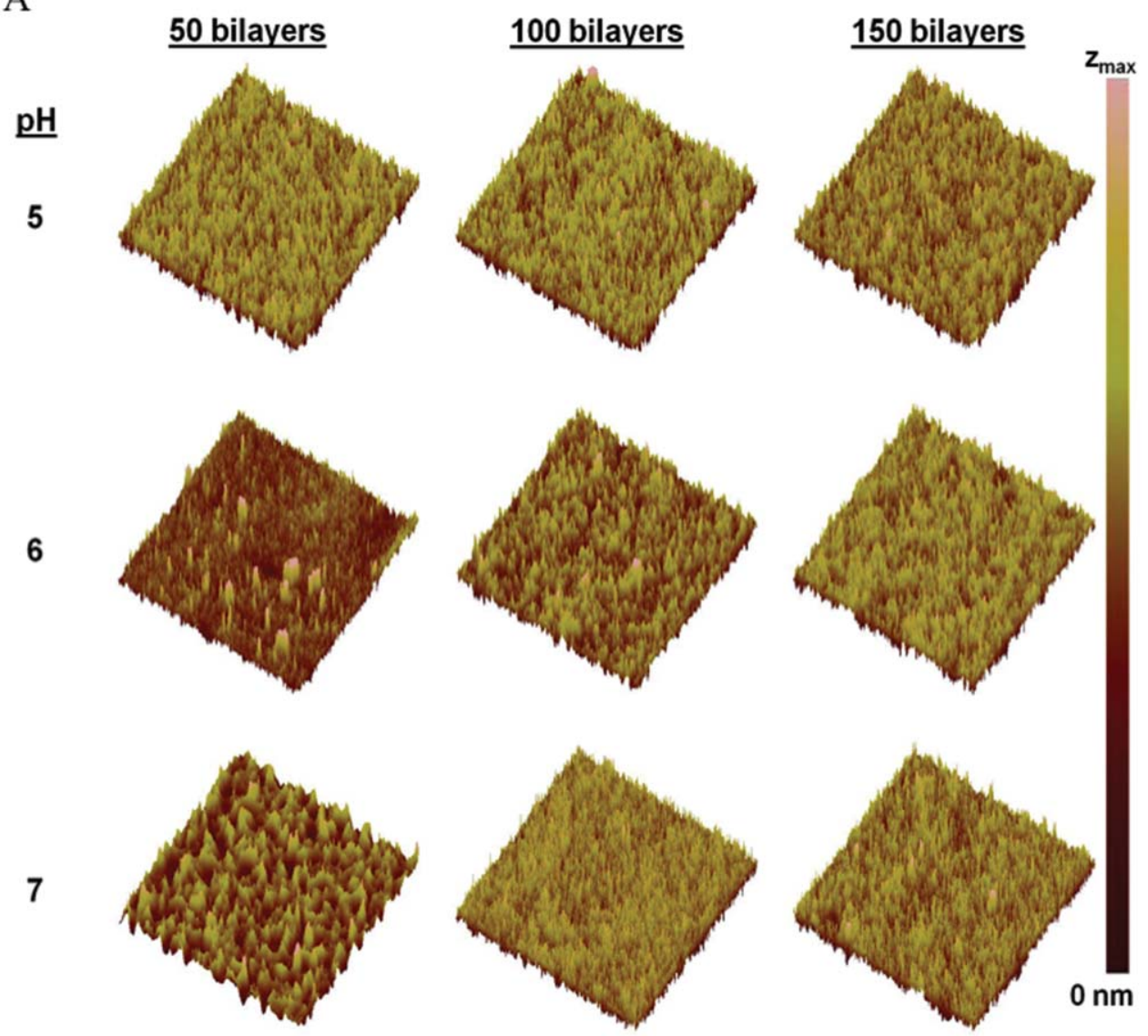

B

\begin{tabular}{|c|c|c|c|}
\hline & \multicolumn{3}{|c|}{ Roughness (nm) } \\
\hline \# of Bilayers & $\mathbf{p H}=\mathbf{5}$ & $\mathbf{p H}=\mathbf{6}$ & $\mathbf{p H}=\mathbf{7}$ \\
\hline $\mathbf{5 0}$ & $3.14 \pm 2.45$ & $0.88 \pm 0.23$ & $2.65 \pm 1.41$ \\
\hline $\mathbf{1 0 0}$ & $1.47 \pm 0.36$ & $2.18 \pm 1.45$ & $3.30 \pm 1.52$ \\
\hline $\mathbf{1 5 0}$ & $1.04 \pm 0.20$ & $1.03 \pm 0.31$ & $1.11 \pm 0.38$ \\
\hline
\end{tabular}

FIGURE 3. Film topography and roughness. A. Atomic force microscopy images show the surface topography (10 $\mu \mathrm{m} \times 10 \mu \mathrm{m})$ for (poly-Llysine/hyaluronic acid) $n$ films $\left(z_{\max }=500 \mathrm{~nm}\right)$, representative of the entire film area for the different conditions tested. Films exhibited uniform roughness over the sprayed area. The lowest roughness values were obtained for $n=150$. B. Root mean squared (RMS) film roughness. Data are mean \pm standard deviation, compared by one-way ANOVA Tukey's post hoc multiple comparison test. No significant differences between the different $\mathrm{pHs}$ were found: $p$ value $=0.5181$ for one-way ANOVA. [Color figure can be viewed in the online issue, which is available at wileyonlinelibrary.com.]

in $400 \mu \mathrm{L}$ of CnT-57 medium. The appropriate amount of culture medium was then added outside the scaffold containing inserts, in order to obtain the same medium level inside and outside the inserts and completely cover the cells. Once keratinocytes reached confluence on the membranes, the media was changed to the CnT-02-3DP media, and after $15 \mathrm{~h}$, exposed to the air-liquid interface. Cells were cultured at $37^{\circ} \mathrm{C}$ and $5 \% \mathrm{CO}_{2}{ }^{32}$ Cellular DNA was quantified using the PicoGreen ${ }^{\circledR}$ dsDNA kit, according to manufacturer instructions. The cell content was removed from the scaffolds by freezing them at $-80^{\circ} \mathrm{C}$ and subse- quent sonication. Fluorescence of samples and standards was measured using 485-nm excitation light at an emission wavelength of 528-nm. The DNA concentration was extrapolated from a previously established standard curve. A LIVE/ DEAD ${ }^{\circledR}$ viability/cytotoxicity kit for mammalian cells was used to test for keratinocyte viability at days 3, 7, and 14 . Calcein-AM and ethidium homodimer-1 were dissolved in PBS at a concentration of 2 and $4 \mu M$, respectively. Keratinocytes growing on the LbL film-coated silicon wafers were incubated for $20 \mathrm{~min}$ at $37^{\circ} \mathrm{C}$ and $5 \% \mathrm{CO}_{2}$ with the LIVE/ $\mathrm{DEAD}{ }^{\circledR}$ kit solutions. After washing twice with $\mathrm{PBS}$, the 


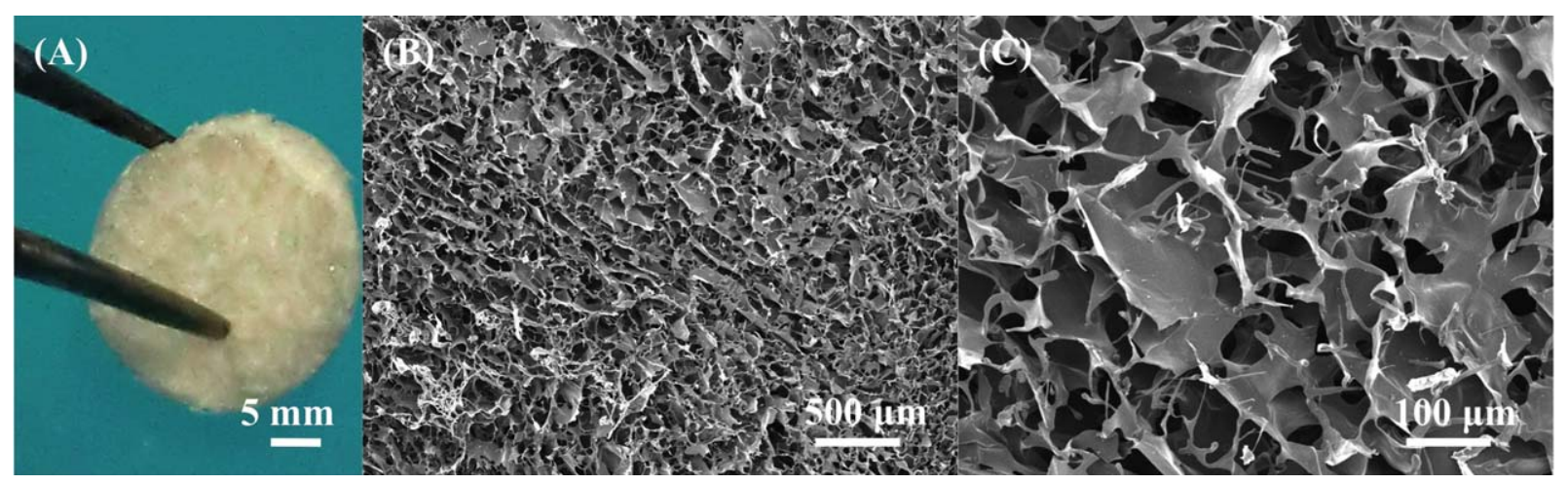

FIGURE 4. Hyaluronic acid (HA) scaffold. A. HA scaffold after freeze-drying, held by forceps. B and C. SEM images of the scaffolds at different magnifications. [Color figure can be viewed in the online issue, which is available at wileyonlinelibrary.com.]

fluorescence of cells on the wafers was observed using fluorescence microscopy.

Silicon wafers or scaffolds previously seeded with cells were fixed overnight using a solution of $2 \%$ glutaraldehyde, $3 \%$ paraformaldehyde, $5 \%$ sucrose, $7 \%$ sodium cacodylate $(0.1 \mathrm{M})$, and $1.5 \%$ water at a $\mathrm{pH}$ of 7.4 . Samples were washed twice ( 5 min each) in sodium cacodylate buffer 0.1 $M$ ) and immersed in a post fixative solution prepared with $2 \mathrm{~mL}$ of $4 \%$ osmium tetroxide, $1 \mathrm{~mL}$ of acetate-veronal, 1 $\mathrm{mL}$ of $\mathrm{HCl}$, and $1.75 \mathrm{~mL}$ of water. The samples were dehydrated with a graded series of ethanol, 50, 70, 90, 95, 100, $100,100 \%, 10-30$ min per step. The ethanol was removed by critical point drying, and once the samples were sputtered with gold, they were imaged via SEM.

\section{Statistical analysis}

Experiments were performed using four samples per condition. Data are presented as mean \pm standard deviation, with $n=4$ for each group, compared by one-way ANOVA Tukey's post hoc multiple comparison test or by an unpaired $t$-test using GraphPad Prism 5.

\section{RESULTS AND DISCUSSION}

\section{Layer-by-layer film growth and morphology}

Using an automated spray-assisted LbL system, we were able to sequentially deposit hyaluronic acid (HA) and poly-Llysine (PLL) on top of both flat silicon substrates and porous HA scaffolds in a fast and controlled manner. A low molecular weight HA (64 kDa) was used to control solution viscosity, such that the HA solution could easily be aerosolized for the spray LbL assembly process. Prior to cell culture and in order to understand the growth mechanisms of the LbL films using spray-assisted LbL, we sprayed the polyelectrolyte films, (PLL/HA) $n$, at $\mathrm{pH} \mathrm{5,} \mathrm{6,} \mathrm{and} 7$ with $n=50$, 100, and 150 bilayers on silicon wafers. PLL/HA films assembled via dip LbL assembly have been observed to have different properties based on their assembly $\mathrm{pH}^{33} \mathrm{We}$ examined sprayed film properties for assembly $\mathrm{pH}$ values close to a physiologic $\mathrm{pH}$ of $\sim 7$. We limited our analysis to the $\mathrm{pH}$ range of 5-7, ensuring minimal film reorganization in cell culture applications and eventual in vivo applications. The film thickness at these conditions was quantified using profilometry (Fig. 2). Film thickness increased with the number of bilayers deposited for all $\mathrm{pH}$ conditions tested. Although the thickest film was built using 150 bilayers at pH $7(1683 \pm 291 \mathrm{~nm})$, the thickness results were not statistically significant between different $\mathrm{pH}$ values, disabling conclusions regarding the influence of $\mathrm{pH}$ on the growth mechanism of the films. In the $\mathrm{pH}$ range examined, both HA and PLL are in the highly charged state, leading to similar LbL film thickness values at each $\mathrm{pH}$ with linear growth behavior between 50 and 150 bilayers.

The $\sim 100 \mathrm{~nm} /$ bilayer growth behavior and apparent linear growth are both features previously reported for PLL/ HA multilayers, which undergo exponential growth due to interdiffusion from $\sim 9$ to 13 bilayers, related to the unique ability of PLL to migrate in and out of the growing multilayer film. ${ }^{11,34}$ These films typically level off to a constant but relatively large thickness per bilayer pair beyond the first 8-10 bilayers. ${ }^{11}$ Films of 50, 100, and 150 bilayers were generated using spray-LbL to create films that range from $\sim 5$ - to $15-\mu \mathrm{m}$ thick. We have previously shown that spray-LbL assembly can lead to inhibition of the superlinear growth process due to the suppression of interdiffusion in the sprayed films and to the kinetic trapping of polyelectrolyte chains on the film surface during spray deposition $^{35}$; however, with the conditions and the polyelectrolytes examined in this study, this phenomenon was not observed.

Atomic force microscopy (AFM) was used to characterize the film topography and quantify film roughness. Selected atomic force microscopy images representative of the entire film area for 50, 100, and 150 bilayer films assembled at $\mathrm{pH} 5,6$, and 7 show that the films were uniformly spread on the surface of the silicon wafer [Fig. 3(A)]. The root mean squared (RMS) roughness values obtained for these films [Fig. 3(B)] indicated a uniform roughness ranging from $0.88 \pm 0.23 \mathrm{~nm}$ to $3.30 \pm 1.52 \mathrm{~nm}$. Overall the lowest roughness values were obtained for 150 bilayer films. No statistically significant differences were observed in roughness for the different assembly pH values tested, indicating that film assembly is relatively unaffected between different $\mathrm{pH}$ values, which can be expected in this narrow $\mathrm{pH}$ range. For other polymer multilayers, it has been observed that 


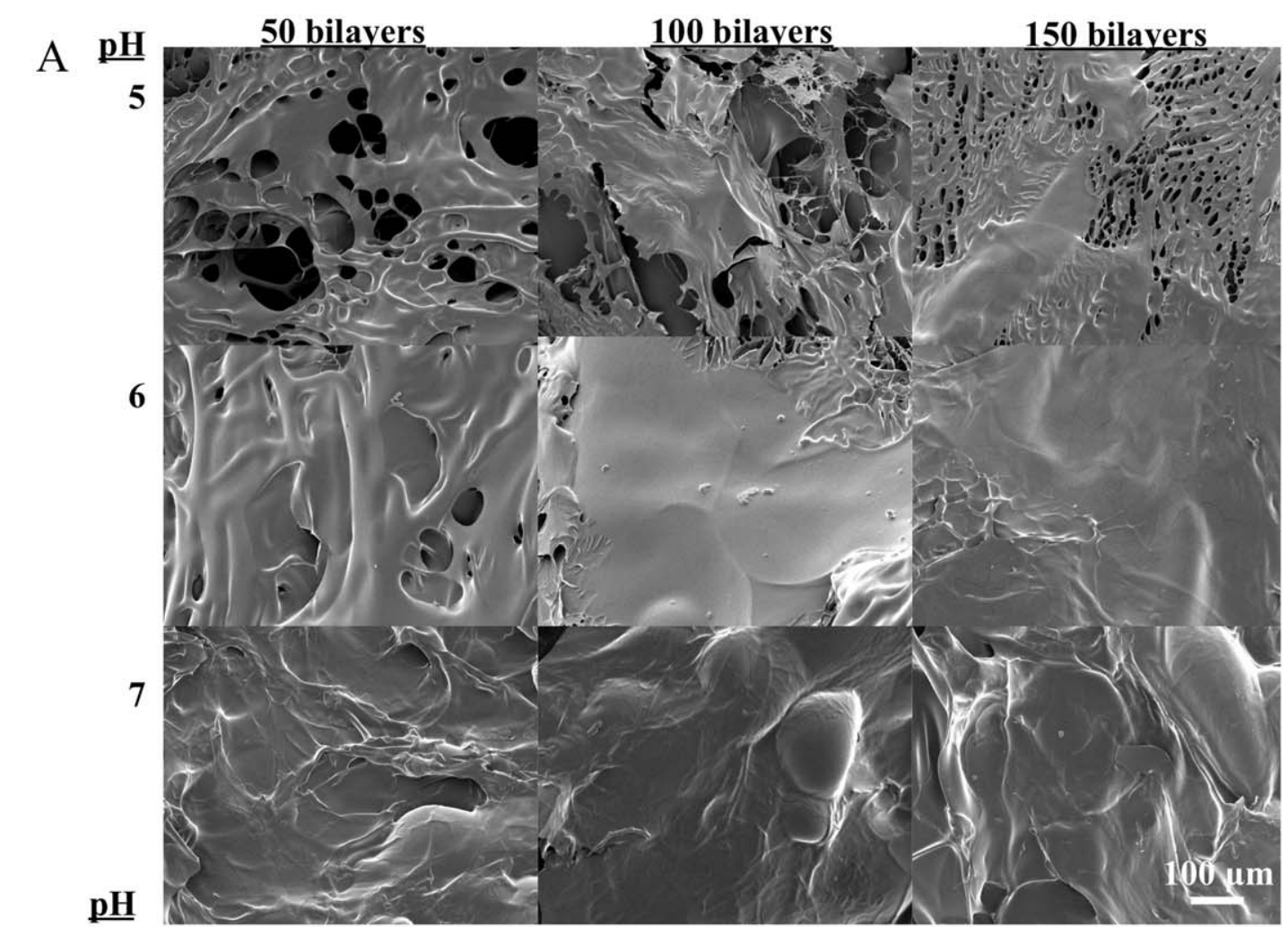

B

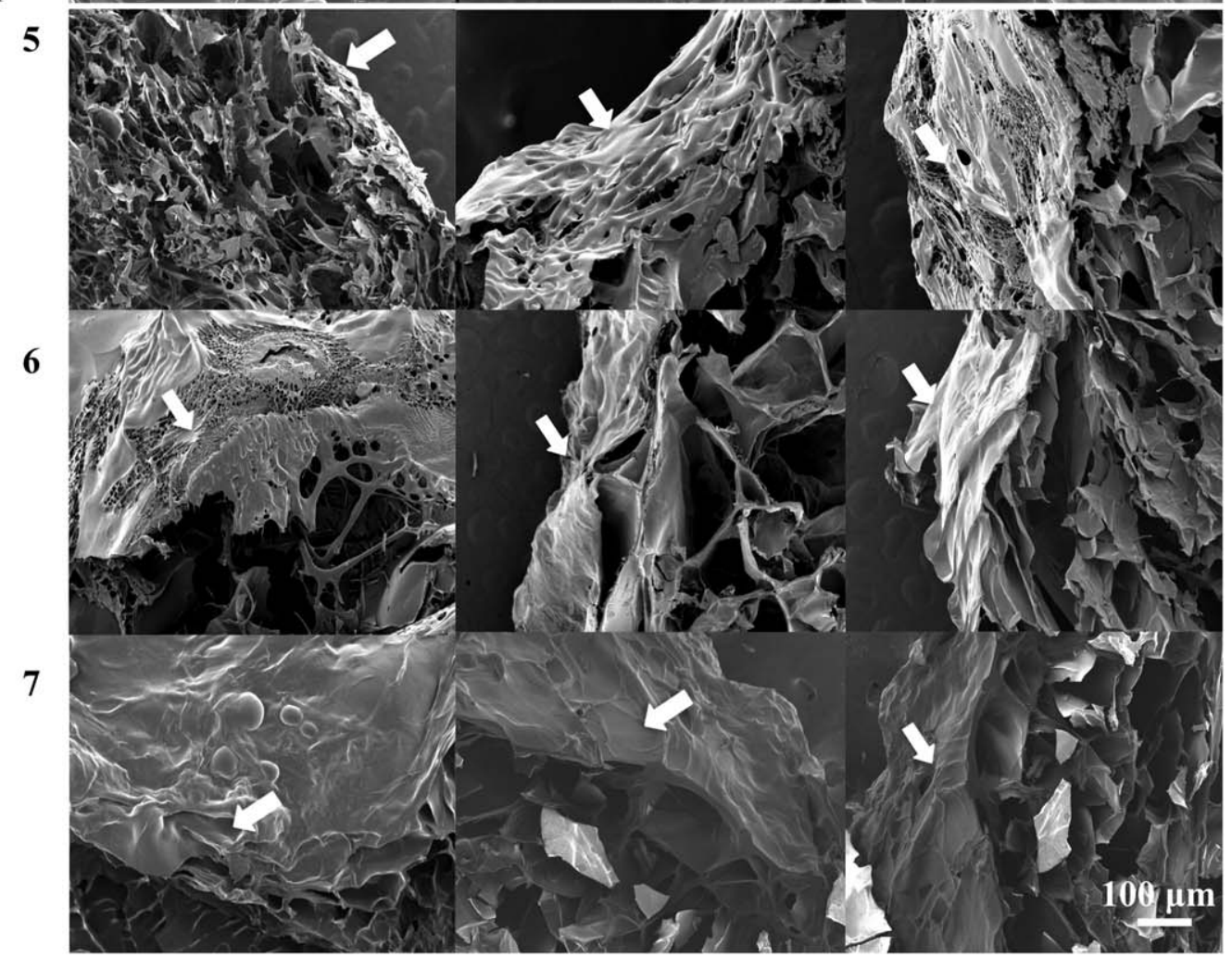

FIGURE 5. Layer-by-layer films coated on hyaluronic acid scaffolds. A. Top view. B. Transverse cut view (arrows indicate the direction of the section). 


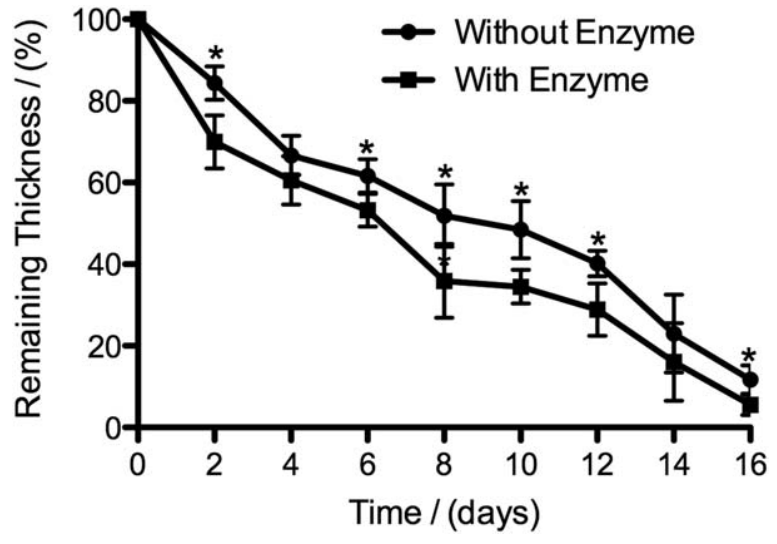

FIGURE 6. Change in film thickness with and without hyaluronidase in PBS at $37^{\circ} \mathrm{C}$ for (poly-L-lysine/hyaluronic acid) 150 assembled at $\mathrm{pH}$ 7. In the presence of the enzyme, the average film thickness loss is $11.8 \%$ per day, while in PBS without enzyme it is $11 \%$ per day. Data are mean \pm standard deviation; differences in means are not significant for day 0,4 , and 14 , but are significant $\left(^{*}\right)$ for the other time points $(p<0.05)$ evaluated via an unpaired $t$-test.

sprayed films usually present much lower roughness values compared to dipped films. ${ }^{35}$

After studying film growth and topography on the surface of silicon wafers, we tested the possibility of depositing (PLL/HA) $n$ films on top of porous HA scaffolds. High molecular weight (MW) (1.2-1.8 MDa) and low MW (351-600 $\mathrm{KDa}$ ) HA were functionalized respectively with aldehyde (HA-CHO) and hydrazide (HA-ADH) groups, as described previously. ${ }^{31,36-39}$ For the HA-ADH, ADH was introduced in the HA sugar unit and for the HA-ALD, the aldehyde groups were introduced by reaction with sodium periodate, that oxidizes the proximal hydroxyl groups to create dialdehydes, thereby opening the sugar ring. ${ }^{31} \mathrm{HA}-\mathrm{CHO}$ and $\mathrm{HA}-\mathrm{ADH}$ were mixed at equivalent molar ratios, forming cross-linked HA gels, HAX, by hydrazone bonds. A viscous and resilient gel was formed right after crosslinking. Subsequent freezedrying of the gel generated an open microstructure with a high degree of interconnectivity. After freezing at $-20^{\circ} \mathrm{C}$ and lyophilization, a white and porous spongy structure was obtained [Fig. 4(A)]. The average pore size determined by SEM image analysis was $183.8 \pm 38.7 \mu \mathrm{m}$ [Fig. 4(B,C)]. The scaffolds in which the (PLL/HA)n films were deposited were also observed under SEM; the top view of the scaffold and its cross section are shown in Figure 5(A,B), respectively. As more film bilayers were deposited, the LbL film progressively coated the scaffold, creating a film bridging the topmost surface, while keeping an intact porous bottom structure. Similar morphologies of sprayed-LbL films have been observed on electrospun membranes. ${ }^{30,40}$ The polyelectrolyte chains begin to fill the gaps between fibers, and as serial deposition continues, the coating grows laterally, filling in interstitial voids. ${ }^{30}$ As the sprayed polymers are first adsorbed on the scaffold, before starting to build a continuous film, the coating becomes more homogeneous with an increasing number of layers. SEM confirmed that the deposition of 50-150 bilayer films led to uniform coatings across the surface of the scaffolds for all $\mathrm{pH}$ values tested.
No significant differences in film morphology were found for the same number of layers in the study at the different $\mathrm{pH}$ values. It has previously been shown that conformal spray-LbL coatings on porous electrospun mats can be developed in the absence of a pressure gradient. The polyelectrolyte chains arriving at the surface initially fill the gaps between fibers, as the mat catches the polyelectrolyte droplets that arrive at the surface through favorable interfacial interactions. As serial deposition continues, the coating grows laterally, filling interstitial voids, rather than penetrating the depth of the mat. ${ }^{41}$ In our case, the HA scaffold likely behaves similarly to these electrospun materials during LbL film deposition.

\section{Characterizing layer-by-layer film erosion}

From the conditions tested, we selected the $\mathrm{pH} 7$ deposition condition for further evaluation, as this is closest to a physiologic $\mathrm{pH}$ of 7.4, thus ensuring more stable films at in vitro conditions; the 150 bilayer film samples were chosen for further studies with cells. This number of layers was selected in order to create a film that would form the best barrier at the dermal-epidermal porous interface, acting as a flat membrane for keratinocyte adhesion.

Consequently, we proceeded to examine erosion of 150 bilayer films assembled on silicon wafers at $\mathrm{pH} 7$ by incubating the samples in PBS with and without $10 \mathrm{U} \mathrm{mL}^{-1}$ of hyaluronidase (an enzyme that degrades HA) in an orbital shaker at $37^{\circ} \mathrm{C}$. Film erosion was evaluated by quantifying the decrease in film thickness over time by profilometry. Figure 6 shows the change in film thickness. The film thickness decreased linearly $\left(R^{2}\right.$ of 0.97 and 0.95 without and with enzyme, respectively). Loss in thickness was monitored for 16 days, after which, it was no longer possible to accurately quantify the thickness, as the films were too thin. Overall, the presence of the enzyme appeared to accelerate the decrease in film thickness. In the presence of the

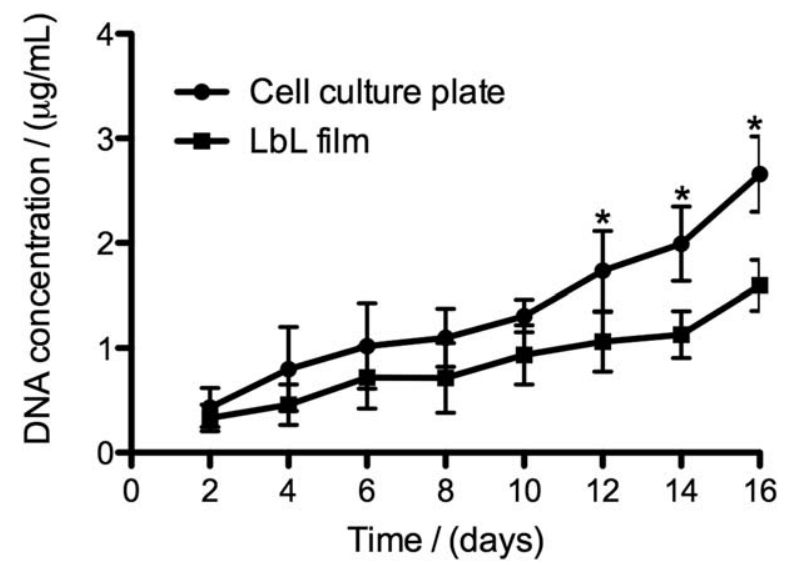

FIGURE 7. Double-stranded DNA quantification represents the proliferation of keratinocytes on (poly-L-lysine/hyaluronic acid)150.5 filmcoated substrates. Cells growing on tissue culture plates, starting with the same initial cell concentration were used as a control. Data are mean \pm standard deviation; difference in means are not significant for days $2,4,6,8$, and 10 , but are significant for days 12, 14, and 16 ( ${ }^{*} p<0.05$, evaluated via an unpaired $t$-test). 

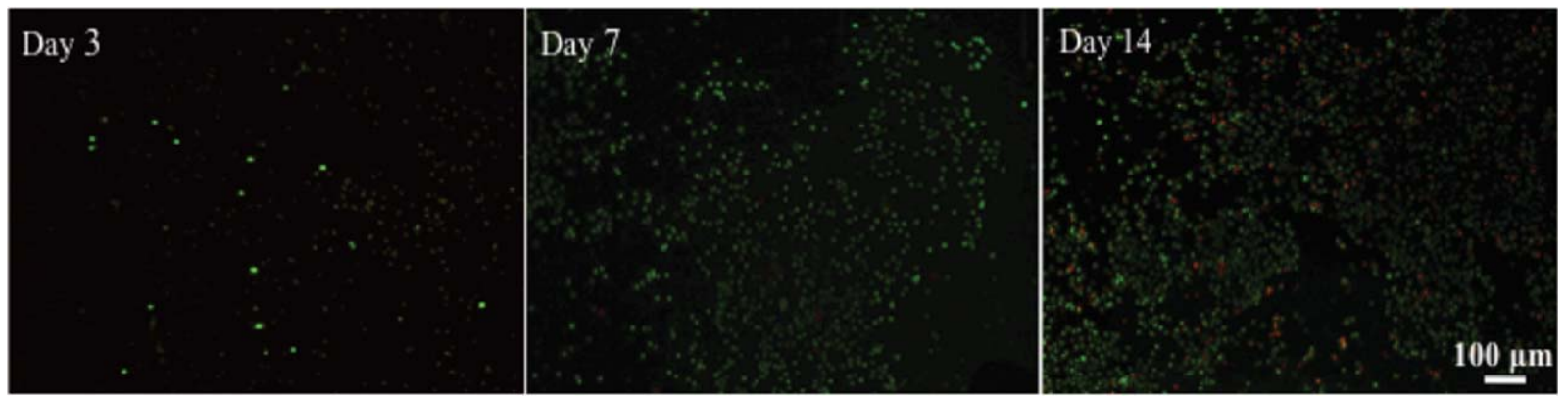

FIGURE 8. LIVE/DEAD $B$ viability/cytotoxicity assay for keratinocytes growing on (poly-L-lysine/hyaluronic acid)150.5 film-coated substrate. Three days after seeding, the keratinocytes started the formation of colonies, which colonized the layer-by-layer film by day 7 . At day 14 , the keratinocytes formed a confluent layer and some cells started to detach. Calcein-AM stains live cells in green and propidium iodide stains dead cells in red. [Color figure can be viewed in the online issue, which is available at wileyonlinelibrary.com.]

enzyme, half of the film was lost by the sixth day, with an average thickness loss of $11.8 \%$ /day, while in PBS without enzyme, $50 \%$ of thickness was lost by the 8th day with an average film loss of $11 \%$ /day. These numbers suggest that although hyaluronidase assists in film breakdown, the primary erosion mechanism is unrelated to enzymatic degradation. It is likely that gradual film swelling and some amount of charge shift on the HA backbone leads to gradual destabilization and disassembly of the film. In addition, the use of a low MW HA may contribute to faster erosion as compared to films containing larger MW HA. The erosion may have also been accelerated due to the way in which we conducted our erosion experiment. The shear stress induced by the orbital shaker likely promoted increased film erosion compared to static conditions. An increase in ionic strength of the PBS as compared to the sodium acetate film deposition buffer may also have contributed to film erosion, as charge shielding at these higher salt concentrations can lead to film destabilization. ${ }^{42}$ For a skin tissue engineering application, our (PLL/HA) film would act as a substrate for initial keratinocyte attachment. The film would then degrade as the new skin epithelium forms. Keratinocytes tend to aggregate yielding complete monolayers by 3-4 days in culture. At around 6 days, a second layer forms, which consists of cells with an extensive internal network of fibrils. ${ }^{43}$ Therefore, the 16 days over which films persist in vitro should be sufficient to ensure healthy keratinocyte adhesion in future applications.

\section{Keratinocyte behavior on layer-by-layer films}

Adult skin consists of two tissue layers: epidermis and dermis. ${ }^{44}$ The uppermost layer of skin, the epidermis, consists primarily of keratinocytes, which form an effective protective barrier for the body. ${ }^{45,46}$ In the healthy skin, the basal keratinocyte layer attaches to a carpet of specialized matrix, the basal lamina. ${ }^{44}$ Here, we tried to mimic the basal lamina with our LbL membrane. HA-based gels and HA-coated surfaces have previously been shown to be non-adhesive to cells. ${ }^{4-49}$ Because HA is highly hydrophilic, we added an extra layer of PLL to the top of the assembled films, in order to improve cell adhesion, yielding (PLL/HA)150.5 (0.5 denotes the extra PLL layer). (PLL/HA) LbL films have previously been used to functionalize photocrosslinked HA hydrogels in order to improve cell adhesion. ${ }^{25}$ Furthermore, PLL has been widely used as a cell adhesive. ${ }^{49}$

We were able to successfully seed human adult keratinocytes on our (PLL/HA)150.5-coated substrates. To verify keratinocyte proliferation, double-stranded DNA (dsDNA) content was quantified up to 16 days following initial keratinocyte seeding on the LbL film-coated samples (Fig. 7). At earlier time points, cells proliferated on the LbL films at similar rates to cells on tissue culture plastic. However, at later time points $(12,14$, and 16 days), the dsDNA content for cells on the LbL film-coated substrates was significantly lower when compared to the tissue culture plate. This behavior is likely primarily due to the gradual disassembly and erosion of the underlying LbL film. Cell viability studies were carried out using LIVE/DEAD ${ }^{\circledR}$ assays on keratinocytes seeded on LbL film-coated silicon substrates. Figure 8 provides representative images of cells on these LbL films, which show that most of the cells remain viable (green color) at 3, 7, and 14 days in culture. On the 14th day, the high cell density at confluence leads to increased cell death (red color) compared to earlier time points and detachment of some cells.

Next, we observed the morphology of adult human keratinocytes on LbL films with SEM. After $24 \mathrm{~h}$ in culture, the keratinocytes seeded on film-coated silicon wafers, were adherent to the surface, with a typical morphology. Figure 9(A) shows the evident adhesion sites and prominent nuclei. For films coating the tops of the 3D porous HA scaffolds, cells attached after 3 days in culture, showing the typical cuboidal morphology of basal keratinocytes (early stage of maturation) [Fig. 9(B)]. ${ }^{50}$ An increase in cell number was observed after 7 days in culture [Fig. $9(\mathrm{C})$ ], confirming proliferation. After 10 days in culture [Fig. 9(D)], the LbL film was completely covered by a sheet of keratinocytes that displayed a flattened cell morphology, characteristic of suprabasal cells. ${ }^{43}$ At days 12 and 14, keratinocytes exhibited increased size, flattened morphology and strong adherence to the film-coated substrate [Fig. $9(\mathrm{E}, \mathrm{F})]$. At day 16, cells appeared rounded and unhealthy [Fig. 9(G)], suggesting keratinization of the epithelial cells by day 18 [Fig. 9(H)] (later stage of maturation). ${ }^{51}$

The successful attachment and proliferation of keratinocytes cultured on top of the (PLL/HA)150.5 film-coated 

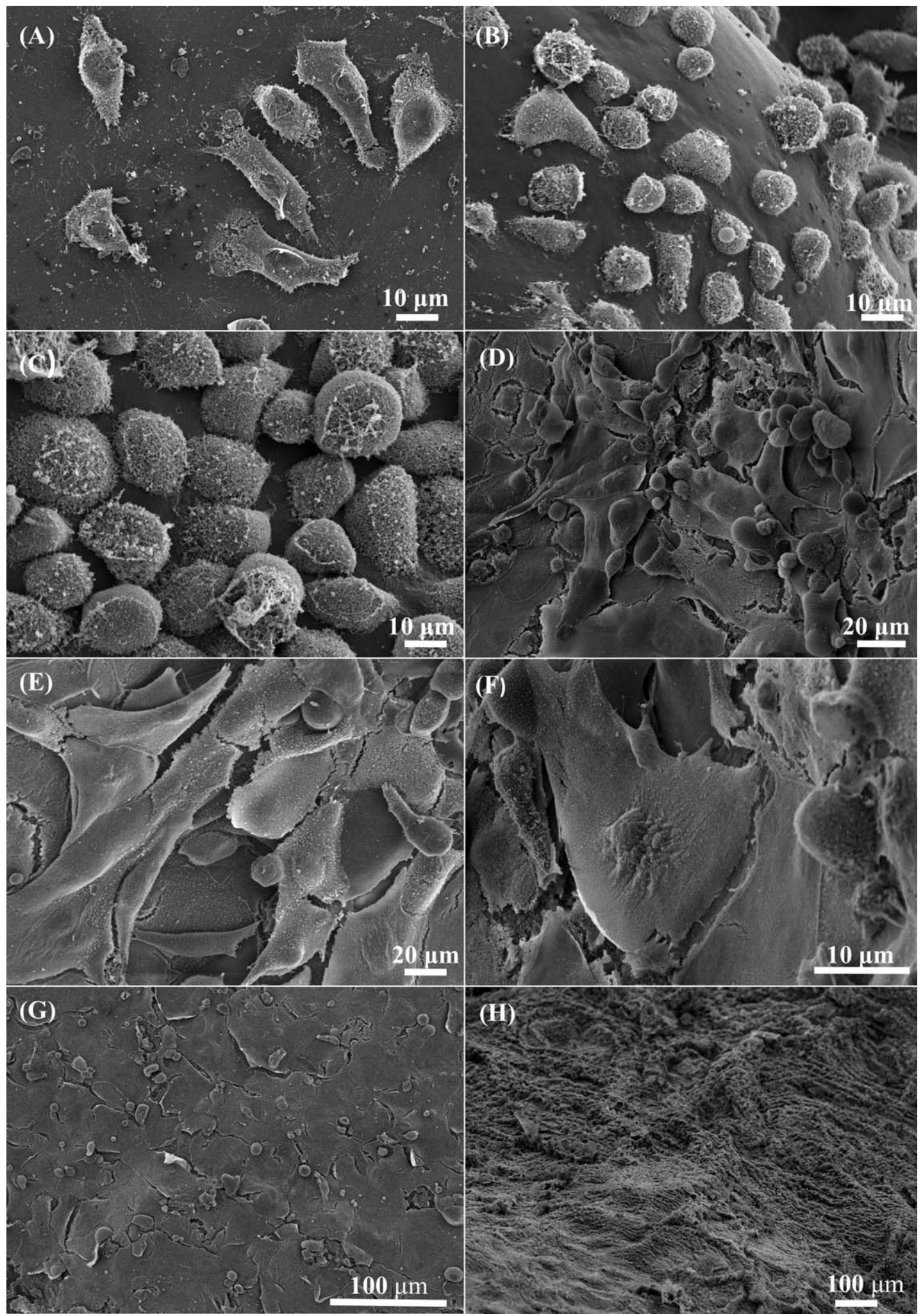

FIGURE 9. Scanning electron microscopy images of keratinocytes cultured on top of (poly-L-lysine/hyaluronic acid)150.5 films assembled at pH 7. A. Cells on film-coated silicon substrates $24 \mathrm{~h}$ after seeding. Cells on film-coated hyaluronic acid scaffolds at B. day 3, C. day 7, D. day 10, E. day 12 , F. day 14 , G. day 16 , and H. day 18. 
porous HA scaffolds developed in this work opens up the possibility of using this bilayer scaffold for skin tissue engineering applications. The LbL film would act as the epidermal component and the porous scaffold as the dermal component. Here we have demonstrated how to build a dermal-epidermal scaffold that could be used to co-culture cells in the epidermis and dermis portions, allowing the interactions between the different cell types, which could promote the healing process. ${ }^{52,53}$ It has previously been shown that in the presence of fibroblasts, keratinocytes have better proliferation and are able to give rise to an improved basement membrane and a thicker epithelium. An increased production of laminin and type IV collagen has also been noted for such co-culture systems. ${ }^{54,55}$ In the scaffold we have developed, the LbL membrane would contribute towards cohesion of the epidermal and dermal components, serving as the interface and the exchange zone between cell layers, allowing the interaction between different types of cells. Consequently, the polyelectrolyte multilayer would help in the assembly of the three-dimensional stratified epidermis and contribute to the reconstruction of a dermal-epidermal junction, resembling a basement membrane. This would improve the strength of tissue engineered skin and better mimic in vivo tissue. Our LbL film could also be loaded with angiogenic growth factors, tuned to release over timescales required to recruit endothelial cells, in order to promote the tissue vascularization necessary for skin regeneration.

\section{CONCLUSION}

We have successfully developed a polyelectrolyte multilayer film, which adheres to the surface of a porous scaffold, is stable yet degradable, and is compatible for biological applications. This LbL thin film, together with the underlying porous hyaluronic acid scaffold creates a single, epidermaldermal structure for potential use in skin tissue engineering applications. The specific properties of each component are addressed in order to potentially favor the formation of the normal skin architecture and consequently, the regeneration of a basal lamina and the stratification of keratinocytes. The epidermal component is flat, enabling the formation of a monolayer of keratinocytes, as demonstrated in this work, and the dermal component is porous in order to promote three-dimensional dermal matrix formation that may ultimately enable culture of dermal fibroblasts.

\section{ACKNOWLEDGMENTS}

This work made use of the Institute for Soldier Nanotechnologies and the Hammond and Langer Laboratories at MIT. The authors thank Timothy McClure and the Center for Materials Science and Engineering at MIT for assistance with profilometry. Scanning electron microscopy was carried out at the Whitehead Institute for Biomedical Research; the authors acknowledge Nicki Watson for her technical support.

\section{REFERENCES}

1. Balasubramani M, Kumar TR, Babu M. Skin substitutes: A review. Burns 2001;27:534-544.
2. Herndon DN, Barrow RE, Rutan RL, Rutan TC, Desai MH, Abston S. A comparison of conservative versus early excision. Therapies in severely burned patients. Ann Surg 1989;209:547-552; discussion 552-553.

3. Bottcher-Haberzeth S, Biedermann T, Reichmann E. Tissue engineering of skin. Burns 2010;36:450-460.

4. Huang S, Zhang YJ, Tang L, Deng ZH, Lu W, Feng F, Xu XL, Jin $Y$. Functional bilayered skin substitute constructed by tissueengineered extracellular matrix and microsphere-incorporated gelatin hydrogel for wound repair. Tissue Eng A 2009;15:26172624.

5. Groeber F, Holeiter M, Hampel M, Hinderer S, Schenke-Layland K. Skin tissue engineering-In vivo and in vitro applications. Adv Drug Deliv Rev 2011;63:352-366.

6. Uccioli L, Giurato L, Ruotolo V, Ciavarella A, Grimaldi MS, Piaggesi A, Teobaldi I, Ricci L, Scionti L, Vermigli C, Seguro R, Mancini L, Ghirlanda G. Two-step autologous grafting using HYAFF scaffolds in treating difficult diabetic foot ulcers: Results of a multicenter, randomized controlled clinical trial with longterm follow-up. Int J Low Extrem Wounds 2011;10:80-85.

7. Caravaggi $C$, De Giglio R, Pritelli $C$, Sommaria M, Dalla Noce S, Fagila E, Mantero M, Clerici G, Fratino P, Dalla Paola L, Mariani G, Mingardi R, Morabito A. HYAFF 11-based autologous dermal and epidermal grafts in the treatment of noninfected diabetic plantar and dorsal foot ulcers-A prospective, mulicenter, controlled, randomized clinical trial. Diabetes Care 2003;26:2853-2859.

8. Uccioli L. A clinical investigation on the characteristics and outcomes of treating chronic lower extremity wounds using the tissuetech autograft system. Int J Low Extrem Wounds 2003;2: 140-151.

9. Uccioli L, Italia TAS. Clinical results related to the use of the TissueTech Autograft System in the treatment of diabetic foot ulceration. Wounds Compendium Clin Res Practice 2003;15:279-288.

10. Price RD, Das-Gupta V, Leigh IM, Navsaria HA. A comparison of tissue-engineered hyaluronic acid dermal matrices in a human wound model. Tissue Eng 2006;12:2985-2995.

11. Picart $C$, Lavalle $P$, Hubert $P$, Cuisinier FJG, Decher $G$, Schaaf $P$, Voegel JC. Buildup mechanism for poly(L-lysine)/hyaluronic acid films onto a solid surface. Langmuir 2001;17:7414-7424.

12. Crouzier T, Ren K, Nicolas C, Roy C, Picart C. Layer-by-layer films as a biomimetic reservoir for rhBMP-2 delivery: Controlled differentiation of myoblasts to osteoblasts. Small 2009;5:598-608.

13. Ren K, Crouzier T, Roy C, Picart C. Polyelectrolyte multilayer films of controlled stiffness modulate myoblast cells differentiation. Adv Funct Mater 2008;18:1378-1389.

14. Ghosh S, Kobal I, Zanette D, Reed WF. Conformational contraction and hydrolysis of hyaluronate in sodium-hydroxide solutions. Macromolecules 1993;26:4685-4693.

15. Picart C, Mutterer J, Richert L, Luo Y, Prestwich GD, Schaaf P, Voegel JC, Lavalle P. Molecular basis for the explanation of the exponential growth of polyelectrolyte multilayers. Proc Natl Acad Sci USA 2002;99:12531-12535.

16. Drobnik J. Hyaluronan in drug delivery. Adv Drug Deliv Rev 1991; 7:295-308.

17. $\mathrm{Xu} X$, Jha AK, Harrington DA, Farach-Carson MC, Jia XQ. Hyaluronic acid-based hydrogels: From a natural polysaccharide to complex networks. Soft Matter 2012;8:3280-3294.

18. Lapcik L, Bohdanecky M, Lapcik L, Bakos D. Hyaluronic-acidpreparation, structure, properties, application. Chem Listy 1991; 85:281-299.

19. Ryabina VR, Vasyukov SE, Panov VP, Starodybtsev SG. Obtaining, properties and application of hyaluronic-acid (a review). Khim Farmatsevticheskii Z 1987;21:142-154.

20. Hu M, Sabelman EE, Cao Y, Chang J, Hentz VR. Three-dimensional hyaluronic acid grafts promote healing and reduce scar formation in skin incision wounds. J Biomed Mater Res Appl Biomater 2003;67B:586-592.

21. Yang GP, Lim IJ, Phan TT, Lorenz HP, Longaker MT. From scarless fetal wounds to keloids: Molecular studies in wound healing. Wound Repair Regen 2003;11:411-418.

22. West DC, Hampson IN, Arnold F, Kumar S. Angiogenesis induced by degradation products of hyaluronic acid. Science 1985;228: 1324-1326. 
23. Yasui SC, Keiderling TA. Vibrational circular-dichroism of polypeptides. 8. Poly(lysine) conformations as a function of $\mathrm{Ph}$ in aqueous solution. J Am Chem Soc 1986;108:5576-5581.

24. Kono K, Kimura S, Imanishi Y. Ph-dependent interaction of amphiphilic polypeptide poly(Lys-Aib-Leu-Aib) with lipid bilayermembrane. Biochemistry 1990;29:3631-3637.

25. Yamanlar S, Sant S, Boudou T, Picart C, Khademhosseini A. Surface functionalization of hyaluronic acid hydrogels by polyelectrolyte multilayer films. Biomaterials 2011;32:5590-5599.

26. Hammond PT. Form and function in multilayer assembly: New applications at the nanoscale. Adv Mater 2004;16:1271-1293.

27. Krogman KC, Zacharia NS, Schroeder S, Hammond PT. Automated process for improved uniformity and versatility of layerby-layer deposition. Langmuir 2007;23:3137-3141.

28. Izquierdo A, Ono SS, Voegel JC, Schaaf P, Decher G. Dipping versus spraying: Exploring the deposition conditions for speeding up layer-by-layer assembly. Langmuir 2005;21:7558-7567.

29. Cado G, Kerdjoudj H, Chassepot A, Lefort M, Benmlih $K$ Hemmerle J, Voegel JC, Jierry L, Schaaf P, Frere Y, Boulmedais F. Polysaccharide films built by simultaneous or alternate spray: A rapid way to engineer biomaterial surfaces. Langmuir 2012;28: 8470-8478.

30. Krogman KC, Lowery JL, Zacharia NS, Rutledge GC, Hammond PT. Spraying asymmetry into functional membranes layer-bylayer. Nat Mater 2009;8:512-518.

31. Jia XQ, Colombo G, Padera R, Langer R, Kohane DS. Prolongation of sciatic nerve blockade by in situ cross-linked hyaluronic acid. Biomaterials 2004;25:4797-4804.

32. Freshney RI. Culture of Animal Cells. Hoboken, New Jersey: Wiley; 2010.

33. Burke SE, Barrett CJ. pH-responsive properties of multilayered poly(L-lysine)/hyaluronic acid surfaces. Biomacromolecules 2003; 4:1773-1783.

34. Picart C, Lavalle P, Cuisinier FJG, Decher G, Schaaf P, Voegel JC. Multilayered hyaluronic acid/polysine architectures deposited on solid interfaces. Abstr Pap Am Chem Soc 2002;223:(1-2): Coll 394.

35. Shukla A, Avadhany SN, Fang JC, Hammond PT. Tunable vancomycin releasing surfaces for biomedical applications. Small 2010; 6:2392-2404.

36. Bulpitt $P$, Aeschlimann D. New strategy for chemical modification of hyaluronic acid: Preparation of functionalized derivatives and their use in the formation of novel biocompatible hydrogels. J Biomed Mater Res 1999;47:152-169.

37. Jia XQ, Burdick JA, Kobler J, Clifton RJ, Rosowski JJ, Zeitels SM, Langer R. Synthesis and characterization of in situ cross-linkable hyaluronic acid-based hydrogels with potential application for vocal fold regeneration. Macromolecules 2004;37:3239-3248.

38. Bulpitt $P$, Aeschlimann D. New strategy for chemical modification of hyaluronic acid: Preparation of functionalized derivatives and their use in the formation of novel biocompatible hydrogels. J Biomed Mater Res 1999;47:152-169.

39. Yeo $Y$, Highley CB, Bellas E, Ito T, Marini R, Langer R, Kohane DS. In situ cross-linkable hyaluronic acid hydrogels prevent postoperative abdominal adhesions in a rabbit model. Biomaterials 2006;27:4698-4705.
40. Liu DS, Ashcraft JN, Mannarino MM, Silberstein MN, Argun AA, Rutledge GC, Boyce MC, Hammond PT. Spray layer-by-layer electrospun composite proton exchange membranes. Adv Funct Mater 2013;23:3087-3095.

41. Krogman KC, Zacharia NS, Schroeder S, Hammond PT. Automated process for improved uniformity and versatility of layerby-layer deposition. Langmuir 2007;23:3137-3141.

42. Sukhishvili SA, Granick S. Layered, erasable polymer multilayers formed by hydrogen-bonded sequential self-assembly. Macromolecules 2002;35:301-310.

43. Marcelo CL, Kim YG, Kaine JL, Voorhees JJ. Stratification, specialization, and proliferation of primary keratinocyte cultures. Evidence of a functioning in vitro epidermal cell system. J Cell Biol 1978;79(2, Part 1):356-370.

44. Martin P. Wound healing-Aiming for perfect skin regeneration. Science 1997;276:75-81.

45. Sun TT, Shih C, Green H. Keratin cytoskeletons in epithelial-cells of internal organs. Proc Natl Acad Sci USA 1979;76:2813-2817.

46. Fuchs E. Keratins and the skin. Annu Rev Cell Dev Biol 1995;11: 123-153.

47. Khademhosseini A, Eng G, Yeh J, Fukuda J, Blumling J, Langer $\mathrm{R}$, Burdick JA. Micromolding of photocrosslinkable hyaluronic acid for cell encapsulation and entrapment. J Biomed Mater Res A 2006;79A:522-532.

48. Morra M, Cassineli C. Non-fouling properties of polysaccharidecoated surfaces. J Biomater Sci Polym Ed 1999;10:1107-1124.

49. Khademhosseini A, Suh KY, Yang JM, Eng G, Yeh J, Levenberg S, Langer R. Layer-by-layer deposition of hyaluronic acid and poly-L-lysine for patterned cell co-cultures. Biomaterials 2004;25: 3583-3592.

50. Gilchrest BA, Calhoun JK, Maciag T. Attachment and growth of human keratinocytes in a serum-free environment. J Cell Physiol 1982;112:197-206.

51. Boyce ST, Ham RG. Calcium-regulated differentiation of normal human epidermal keratinocytes in chemically defined clonal culture and serum-free serial culture. J Invest Dermatol 1983; $81(1$ Suppl):33s-40s.

52. Stark HJ, Willhauck WJ, Mirancea N, Boehnke K, Nord I, Breitkreutz D, Pavesio A, Boukamp P, Fusenig NE. Authentic fibroblast matrix in dermal equivalents normalises epidermal histogenesis and dermo-epidermal junction in organotypic co-culture. Eur J Cell Biol 2004;83:631-645.

53. Limat A, Hunziker T, Boillat C, Bayreuther K, Noser F. Postmitotic human dermal fibroblasts efficiently support the growth of human follicular keratinocytes. J Investig Dermatol 1989;92: 758-762.

54. Zacchi V, Soranzo C, Cortivo R, Radice M, Brun P, Abatangelo G. In vitro engineering of human skin-like tissue. J Biomed Mater Res 1998;40:187-194.

55. Boyce ST, Hansbrough JF. Biologic attachment, growth, and differentiation of cultured human epidermal-keratinocytes on a graftable collagen and chondroitin-6-sulfate substrate. Surgery 1988; 103:421-431. 